Review

\title{
Evapotranspiration Estimation with Remote Sensing and Various Surface Energy Balance Algorithms-A Review
}

\author{
Yuei-An Liou * and Sanjib Kumar Kar * \\ Center for Space and Remote Sensing Research, National Central University, Jhong-Li, \\ Taoyuan 32001, Taiwan
}

* Authors to whom correspondence should be addressed; E-Mails: yueian@csrsr.ncu.edu.tw (Y.-A.L.); sanjib_kar@hotmail.com (S.K.K.); Tel.: +886-3-422-7151 (Y.-A.L.); Fax: +886-3-485-5566 (Y.-A.L.).

Received: 7 February 2014; in revised form: 4 April 2014 / Accepted: 17 April 2014 /

Published: 28 April 2014

\begin{abstract}
With the advent of new satellite technology, the radiative energy exchanges between Sun, Earth, and space may now be quantified accurately. Nevertheless, much less is known about the magnitude of the energy flows within the climate system and at the Earth's surface, which cannot be directly measured by satellites. This review surveys the basic theories, observational methods, and different surface energy balance algorithms for estimating evapotranspiration (ET) from landscapes and regions with remotely sensed surface temperatures, and highlights uncertainties and limitations associated with those estimation methods. Although some of these algorithms were built up for specific land covers like irrigation areas only, methods developed for other disciplines like hydrology and meteorology, are also reviewed, where continuous estimates in space and in time are needed. Temporal and spatial scaling issues associated with the use of thermal remote sensing for estimating evapotranspiration are also discussed. A review of these different satellite based remote sensing approaches is presented. The main physical bases and assumptions of these algorithms are also discussed. Some results are shown for the estimation of evapotranspiration on a rice paddy of Chiayi Plain in Taiwan using remote sensing data.
\end{abstract}

Keywords: evapotranspiration; albedo; surface energy balance; remote sensing 


\section{Introduction}

The global energy balance considers the energy flows within the climate system and their exchanges with outer space. In many publications and textbooks, the global mean energy balances are prominently featured through iconic diagrams. However, the actual numbers representing the energy flows in the various pictures exhibit considerable fluctuations [1-6]. This indicates a major uncertainty in our present understanding of the climate system, inherent in assessing some of these fundamental energy flows as shown in Figure 1. Advanced spaceborne observation systems help in determining the energy flows of the climate system at the top of atmosphere (TOA) [7,8], but our technical knowledge is still insufficient for determining the energy flows within the climate system and at the Earth's surface, which are directly immeasurable from satellites. Hence, compared to the top of the atmosphere, the estimation of surface energy fluxes is associated with larger uncertainties, and therefore becomes a topic of greater debates.

Figure 1. Schematic diagram of the global mean annual energy balance $\left(\mathrm{W} \cdot \mathrm{m}^{-2}\right)$ of the Earth. Numerical values are taken from (a) Kiehl el al. [3] and (b) Wild et al. [1].
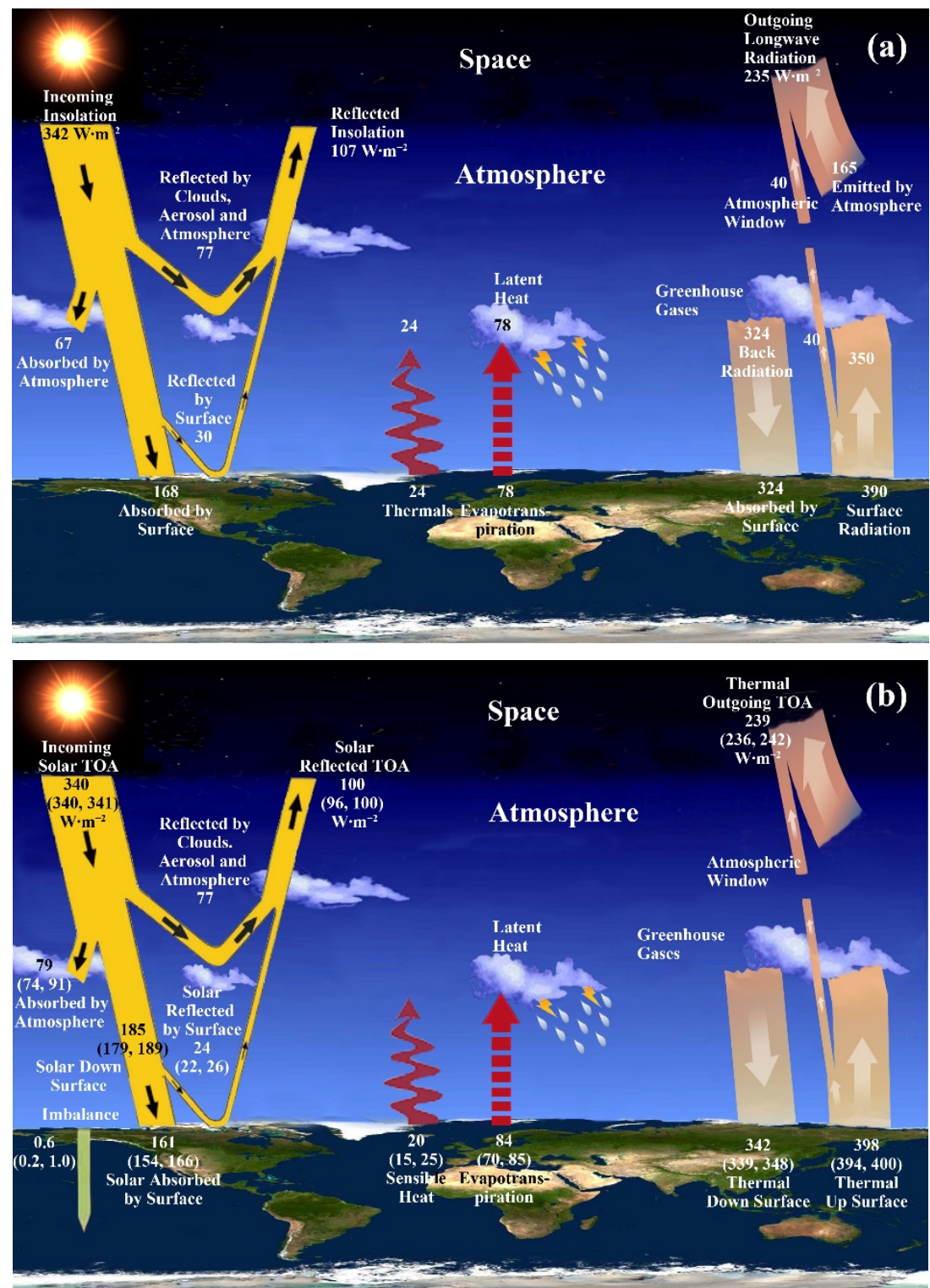
Among the various energy flows within the atmosphere and Earth's surface, the knowledge of both sensible (H) and latent (LE) heat fluxes, as well as of soil moisture content, are of great importance to many environmental applications, including the monitoring of plant water demand, plant growth and productivity, as well as for cultivation and irrigation management systems [9-12]. Such information is essential for numerical modeling of atmospheric and hydrological processes and for improving the accuracy of the models used in weather forecasting [13]. Additionally, quantitative information on these parameters is highly important for monitoring of land degradation and desertification on a regional scale $[14,15]$. Planning and management of land use are therefore closely related to the sustainability of water resources as land use changes are linked with water volume through relevant hydrological processes [16]. Several factors like climate and land use and land cover (LULC) change again affect the hydrological cycle. Quantifying the energy budget above plant canopies is critical for understanding hydrologic cycles, and provides insights for improving modeling of future regional and global climate regimes [17-20]. Hence, conventional techniques like eddy covariance (EC) and Bowen ratio (BR) have been applied to several land uses such as grassland, forest, mango orchard, garlic, grapes, citrus, etc. [21-28]. However, these conventional techniques do not provide spatial trends (or distribution) at the regional scale especially in regions with advective climatic conditions. Evaporation is the primary process by which water is removed from a watershed and transpiration is the process of removing water from vegetation or any other moisture containing living surface. Therefore, evapotranspiration, which is a combined process of evaporation and transpiration, is a crucial factor in the hydrological cycle. ET is the largest outgoing water flux from the Earth's surface; accurate quantifying ET is critical to developing a greater understanding of a range of hydrological, climatic, and ecosystem processes, and beneficial in numerous applications, e.g., water resources management, drought monitoring, improvement of hydrological modeling, weather forecasts, and vulnerability of forest to fire [29,30]. The regional evapotranspiration is more than half of the total precipitation and the amount of evapotranspiration is almost equal to the precipitation in the semi-arid region [31]. Therefore, it is highly essential to gain an in depth understanding about the interaction between LULC and hydrological cycle. Frequent changes in LULC are observed especially in the developing countries which have agriculture based economies and rapidly increasing populations. LULCC is generally classified into two broad categories: conversion and modification [32]. Change from one land cover or land use category to another is referred as conversion, while on the other hand, change within one land use or land cover category due to changes in its physical or functional attributes is referred as modification. Such changes in LULC systems have important consequences for our environment through their impacts on soil moisture and water, biodiversity, and microclimate [33]. Therefore, better knowledge on the influence of land cover changes on the hydrology will help planners to formulate policies to minimize the undesirable effects of future land cover changes.

The ground instrumentation used for the estimation of LE, $H$ fluxes, and soil moisture measurement, offers certain advantages. However, ground-based instruments are generally able to give only localized estimates of the surface energy fluxes and soil moisture content and their employment is often costly, time consuming, labour-intensive and sometimes subject to instrument failure. Integration of ancillary ground information with remote sensing imagery is often able to provide repetitive and synoptic views of crucial parameters characterizing land surface interactions, surface energy fluxes, and surface soil moisture. Various methods have been developed for this purpose using a wide range of 
remote sensing data. Over the last few decades, the advent of satellite remote sensing has led to a substantial amount of work in resolving whether such systems can provide spatially explicit information relating to surface fluxes. Satellite remote sensing techniques have become attractive for the retrieval of these parameters because of their ability to provide repetitive and synoptic views in a spatially contiguous manner without any disturbance and site accessibility issues in the area to be surveyed [34,35]. As a result, various algorithms have been developed utilizing information from various types of remote sensing observations and often in conjunction with ancillary surface and atmospheric observations for the estimation of these parameters. Combined use of satellite data from optical and thermal infrared radiometers has shown evidence for the retrieval of both LE and $\mathrm{H}$ fluxes and soil moisture variations [36-39]. It has been indicated that the thermal infrared remote sensing data is useful for analyzing landscape biophysical characteristics and modeling of landscape ecological processes [40]. These methods vary from purely empirical to more physically based approaches based on the energy balance equation and the information obtained from the "scatterplot" relationships between satellite-derived vegetation index (VI) and surface radiant temperature measures. Various methodologies have been described relatively recently by, for example, Moran et al., Courault et al., Verstraeten et al., Long and Singh, Long et al., Yang and Shang; and Moran and Jackson [41-47].

Evapotranspiration (ET) is a collective term that includes evaporation from vegetation or any other moisture containing living surface (transpiration) and evaporation from the water bodies and soil and is used to describe the loss of water from the Earth's surface to the atmosphere by the combined processes of evaporation and transpiration. Perhaps it is the most difficult hydrological flux to estimate or model especially at regional or global scales in the assessment of water resources and the impact of land use change on these resources. Traditional approaches of ET estimation (e.g., weighing lysimeter, Energy Balance Bowen Ratio (EBBR), eddy covariance techniques, pan-measurement, sap flow, scintillometer, etc.) are mainly based on a variety of complex models and at local, field, and landscape scales. The accurate estimates of ET over a homogeneous area can be made by these conventional techniques. However, such measurements cannot be directly extended to large-scale ET due to natural heterogeneity of the land surface and complexity of hydrologic processes and because of the need for a variety of surface measurements and land surface parameters [48]. Remotely sensed images have provided a promising source of data for mapping regional- and meso-scale patterns of ET on the Earth's surface and surface temperature helps to establish the direct link between surface radiances and energy balance components [49-55]. Information embedded in visible, near-infrared, and thermal infrared band can be used to retrieve the land surface temperature (LST), VI, and atmospheric temperature. These critical surface and atmospheric variables then feed as inputs to simulate surface fluxes and ET based on the energy balance equation. Remote sensing technology can provide a large and continuous spatial coverage within a few minutes. It costs less than when the same spatial information is obtained with conventional measurements and it is the only approach for ungauged areas where man-made measurements are extremely difficult to conduct $[31,56]$. Remotely sensed surface temperature can provide a surface measurement from a resolution of a few $\mathrm{cm}^{2}$ to several $\mathrm{km}^{2}$ from certain satellites [57]. Remote sensing based evapotranspiration estimation and its development has been reviewed from time to time $[40,47,55]$. This issue has been addressed from a hydrological perspective by Overgaard et al. [58] with particular emphasis to plant sciences, agronomy, and irrigation applications [59,60]. Farahani et al. [61] provide a focused survey of progress in crop 
evapotranspiration measurement and modeling with particular emphasis on the aspects of irrigational interest. A comprehensive review is found on ground-based measurements and remote sensing methods for assessing terrestrial evaporation and soil moisture content at multi-scale scale observation [43] while some compact review on various methods for estimating terrestrial evaporation with surface temperatures at various scales are also found in the literature $[62,63]$, but these reviews put emphasis particularly on studies published since the early 1990s. Regional and global scale ET estimation can be made by combining surface parameters obtained from remote sensing data with surface meteorological variables and vegetation characteristics. Remote sensing technique can provide spatial and temporal information of Normalized Difference Vegetation Index (NDVI), Leaf Area Index (LAI), surface albedo, surface emissivity, and radiometric surface temperature, most of which are indispensable to the models and methods that partition the available energy $[63,64]$. Apart from its numerous advantages, satellite remote sensing has shown extra potential to retrieve near-surface variables also. MODIS sensor (the MOD07_L2 product) is among those in which the thermal infrared band information can be used to retrieve air temperature and humidity at 20 vertical levels of the atmospheric profile, including the near-surface at the sea level, which can definitely be corrected for terrain effects and get the near-surface air temperature and humidity [65]. This facility of remote sensing has extended the applications of the energy balance equation to homogeneous areas with uniform vegetation, soil moisture, and topography. A large number of efforts have been made to incorporate remotely sensed surface temperature in combination with other critical variables, e.g., VI and albedo, into ET modeling during the past three decades [62]. These efforts have resulted in the development of a broad range of satellite-based ET models with varying degrees of model inputs and outputs, model-structure complexity and mechanisms and in their advantages and drawbacks. Therefore, considering the characteristics and significance of the various ET methods developed over the past decades, precise estimation of ET over a regional scale based on the remote sensing technology has become a critical question to hydrologists, water resources and irrigation engineers, and climatologists in various ET-related applications and studies. Hence, summaries and comparisons of different remote sensing-based ET estimation methods are needed for a better understanding of the mechanisms involved among the hydrosphere, atmosphere, and biosphere of the Earth.

It was Penman [66] who laid the foundation for relating evapotranspiration to meteorological variables [67]. Thereafter in the 20th century, a substantial progress was made in evapotranspiration processes with energy exchanges. Model simulations or empirical equations requiring meteorological data are the traditional way of estimating evapotranspiration. However, because of some practical reasons like diversity in land covers or temporal changes in the landscape, these methods may not represent the evapotranspiration at a regional scale effectively [68]. The most frequently used method for estimating evapotranspiration at present is the Penman-Monteith equation. It is a point based method and hence not applicable for large heterogeneous areas. Moreover the Penman-Monteith equation often requires a large amount of detailed information that may not be practical to obtain over large areas [69]. Because of these reasons there is a significant need for a remote sensing technology that can give ET value on a continuous basis for shorter time duration. Acquiring data of a large area in an instantaneous view is possible through remote sensing and the data can be utilized to retrieve representative parameters like radiometric surface temperature, VI, albedo, etc. [55,70,71]. The energy balance concept and net radiation are used as the principal parameters in most of the remote sensing 
methods for estimating evapotranspiration [72]. Till date several energy balance algorithms are available for calculating ET through remote sensing. Different algorithms are used by various scientists in different parts of globe and have yielded satisfactory results. In this paper we have reviewed different surface energy balance algorithms, which are used for estimation of ET through remote sensing and their advantages and disadvantages are discussed below.

\section{Surface Energy Balance Models}

The Earth system is operated close to an energy balance, which implies that an equal amount of energy enters into the Earth system and emerges out of it. Consequently, the temperature of the whole system over a long period of time remains relatively unaltered. However, variations over time and space persist within the Earth system. Some of these variations result from the changes in surface conditions, such as whether the surface is land/water, covered by snow/ice, etc. Such variations in surface conditions lead to changes in the surface energy balance. The variations in surface conditions affect the amount of energy retained and distributed in and within the Earth system.

\subsection{Surface Energy Balance}

The surface energy balance at the land-air interface can be written as Equation (1) as follows and the net radiation is considered as a residual of the soil heat flux, the sensible heat flux, and the latent heat flux:

$$
R_{n}=G+H+L E
$$

where $G$ is the soil heat flux $\left(\mathrm{W} \cdot \mathrm{m}^{-2}\right), H$ is the sensible heat flux $\left(\mathrm{W} \cdot \mathrm{m}^{-2}\right)$, and $L E$ is the latent heat flux $\left(\mathrm{W} \cdot \mathrm{m}^{-2}\right)$. Net radiation $\left(R_{n}\right)$ is partitioned into $G, H$, and $L E$. It can be estimated from the sum of the difference between the incoming $\left(R_{S} \downarrow\right)$ and the reflected outgoing shortwave solar radiation $\left(R_{S} \uparrow\right)$ ( 0.15 to $5 \mu \mathrm{m})$, and the difference between the downwelling atmospheric $\left(R_{L} \downarrow\right)$ and the surface-emitted and -reflected longwave radiation $\left(R_{L} \uparrow\right)$.

\subsection{Net Radiation $\left(R_{n}\right)$}

According to the radiation balance, the net radiation can be considered as a balance between incoming and outgoing short-wave and long-wave radiation under steady atmospheric condition:

$$
R_{n}=R_{s} \downarrow+R_{s} \uparrow+R_{L} \downarrow-R_{L} \uparrow
$$

where $R_{n}$ is the net radiation ( $\left.\mathrm{W} \cdot \mathrm{m}^{-2}\right), R_{S} \downarrow$ is the incoming short-wave radiation $\left(\mathrm{W} \cdot \mathrm{m}^{-2}\right.$ ), and $R_{S} \uparrow$ is the outgoing short-wave radiation $\left(\mathrm{W} \cdot \mathrm{m}^{-2}\right.$ ), while $R_{L} \downarrow$ is the incoming long-wave radiation $\left(\mathrm{W} \cdot \mathrm{m}^{-2}\right)$, and $R_{L} \uparrow$ is the outgoing long-wave radiation $\left(\mathrm{W} \cdot \mathrm{m}^{-2}\right)$. The net short-wave radiation can be written as follows:

$$
\sum R_{s}=(1-\alpha) R_{s} \downarrow=(1-\alpha) \cdot\left(S_{c} \times \cos \theta \times d_{r} \times \tau_{a}\right)
$$

where $\alpha$ is the surface albedo, $S_{c}$ is the solar constant $\left(\mathrm{W} \cdot \mathrm{m}^{-2}\right), \theta$ is the solar incidence angle, $d_{r}$ is the relative Earth-Sun distance, and $\tau_{a}$ is the atmospheric transmissivity. 
The incoming long-wave radiation is the downward thermal radiation flux from the atmosphere. The air emissivity can be estimated by a function of the water vapor, pressure, and temperature in the cloudless atmosphere:

$$
R_{L} \downarrow=e_{s k y} \times \sigma \times T_{a}^{4}
$$

where $e_{s k y}$ is the air emissivity, $\sigma$ is the Stefan-Boltzmann constant $\left(\mathrm{W} \cdot \mathrm{m}^{-2} \cdot \mathrm{K}^{-4}\right)$, and $T_{a}$ is the air temperature $(\mathrm{K})$. The outgoing long-wave radiation is computed by using the Stefan-Boltzmann equation:

$$
R_{L} \uparrow=\varepsilon_{0} \times \sigma \times T_{s}^{4}
$$

where $\varepsilon_{0}$ is the surface emissivity and $T_{s}$ is the surface temperature $(\mathrm{K})$.

\subsection{Sensible Heat Flux $(H)$}

The sensible heat flux $(H)$ is the rate of heat loss to the air by convection and conduction due to a temperature difference, which can be written as:

$$
H=\rho_{a i r} C_{p} \frac{d T}{r_{a h}}
$$

where $\rho_{\text {air }}$ is the density of air $\left(\mathrm{kg} \cdot \mathrm{m}^{-3}\right), C_{p}$ is the air specific heat $\left(=1004 \mathrm{~J} \cdot \mathrm{kg}^{-1} \cdot \mathrm{K}^{-1}\right)$, while $d T$ is the difference between the air temperature and the aerodynamic temperature near the surface, $\left(d T=T_{a}-T_{s}\right)$, calculated as set out in the SEBAL Users Manual [73] and $r_{a h}$ is the aerodynamic resistance.

\subsection{Latent Heat Flux (LE)}

Latent heat flux is the rate of latent heat loss from the surface due to evapotranspiration. According to the Equation (1), the latent heat can be written as:

$$
L E=R_{n}-G-H
$$

\section{Different Surface Energy Balance Algorithms}

\subsection{Surface Energy Balance Index (SEBI)}

Based on the contrast between dry and wet regions, Menenti and Choudhury [74] proposed the Surface Energy Balance Index (SEBI) method to derive the evapotranspiration from evaporative fraction. This method is based on the Crop Water Stress Index (CWSI) [75]. In this approach, relative evaporation is determined by scaling an observed surface temperature in a maximum range of surface temperature, denoted by extremes in the surface energy balance suggesting a theoretical lower and upper bounds on the surface and air temperature difference. Here under dry-condition, evaporation is assumed to be zero due to the limitation of water availability in soil for a particular set of boundary layer characteristics so that the sensible heat flux density takes its maximum value $T_{s, \max }$ (maximum surface temperature). $T_{s, \max }$ is inverted from the bulk transfer equation, which is expressed as [76]:

$$
T_{s, \text { max }}=\langle T\rangle_{p b l}+r_{a, \text { max }}\left(\frac{H}{\rho C_{p}}\right)
$$


where $\langle T\rangle_{p b l}$ represents the average planetary boundary layer temperature in K. $r_{a \text {,max }}$ is the maximum aerodynamic resistance to sensible heat transfer $\mathrm{s} / \mathrm{m}$.

The minimum surface temperature is obtained for the wet region from Equation (9) by computing the potential ET from the Penman-Monteith equation considering zero internal resistance:

$$
T_{s, \min }=\langle T\rangle_{p b l}+\frac{\frac{r_{a, \text { min }}\left(R_{n}-G\right)}{\rho c_{p}}-\frac{\left(e_{s a t}-e\right)}{\gamma}}{1+\frac{\Delta}{\gamma}}
$$

where $r_{a, \min }$ represents minimum aerodynamic resistance in $\mathrm{s} / \mathrm{m}$ and $e$ and $e_{\text {sat }}$ stand for actual and saturation vapor pressure, respectively. $\Delta$ is the slope of saturated vapor pressure as a function of $T_{a}$ (air temperature measured at a reference height) in $\mathrm{k} \cdot \mathrm{Pa} /{ }^{\circ} \mathrm{C} \cdot \gamma$ denotes the psychrometric constant in $\mathrm{k} \cdot \mathrm{Pa} /{ }^{\circ} \mathrm{C}$. Interpolating the observed surface temperature with the maximum and minimum surface temperatures, the relative evaporative fraction can then be calculated from the equation given below [76]:

$$
\frac{L E}{L E_{p}}=1-\frac{\Delta T \times r_{a}^{-1}-\Delta T_{\min } \times r_{a, \text { min }}^{-1}}{\Delta T_{\max } \times r_{a, \text { max }}^{-1}-\Delta T_{\min } \times r_{a, \text { min }}^{-1}}
$$

where $\Delta T=T_{s}-T_{p b l}, \Delta T_{\min }=T_{s, \min }-T_{p b l}$, and $\Delta T_{\max }=T_{s, \max }-T_{p b l}$. Surface temperature $T_{s}$ is determined by using image data in the thermal infrared region for each pixel, while $T_{p b l}$ is the air potential temperature at higher elevation or at the top of the Planetary Boundary Layer (PBL). Modifying the CWSI [75], Menenti and Choudhury [74] defined theoretically the pixel-wise ranges for LE and $T_{s}$ to account for surface variability of actual evaporation caused by albedo and aerodynamic roughness. For a surface at particular surface albedo and roughness, pixel-wise maximum and minimum surface temperatures and redefined CWSI as a pixel-wise SEBI are computed to derive the regional ET from the relative evaporative fraction [74].

\subsection{Surface Energy Balance System (SEBS)}

Another well-known model is the Surface Energy Balance System (SEBS). Su [77,78] and Su et al. $[79,80]$ described a modified form of SEBI for the estimation of land surface energy balance using remotely sensed data, which has been named SEBS. SEBS estimates sensible and latent heat fluxes from satellite data and routinely available meteorological data. Computations of land surface physical parameters, calculation of roughness length for heat transfer, and estimation of the evaporative fraction based on energy balance at limiting cases are the main bases of SEBS [70]. In SEBS, the latent heat flux is considered to be zero at the dry limit, which means sensible heat flux reaches its maximum value (i.e., $H_{d r y}=R_{n}-G$ ). On the other hand, at the wet limit, ET takes place at potential rate $\left(L E_{w e t}\right)$, (i.e., the evaporation is restricted only by the energy available for a particular surface and atmospheric condition) and the sensible heat flux attains its minimum value, $H_{\text {wet }}$. The sensible heat flux at dry and wet limits can be expressed as:

$$
H_{d r y}=R_{n}-G
$$




$$
H_{w e t}=\frac{\left(R_{n}-G\right) \gamma}{(\gamma+\Delta)}-\frac{\rho C_{p}\left(e_{s a t}-e\right)}{r_{a}(\gamma+\Delta)}
$$

where $r_{a}$ is dependent on the Obukhov length, which in turn is a function of the friction velocity and sensible heat flux. The relative evaporative fraction $\left(E F_{r}\right)$ and evaporative fraction $(E F)$ then can be expressed as:

$$
\begin{gathered}
E F_{r}=\frac{H_{d r y}-H}{H_{d r y}-H_{w e t}} \\
E F=\frac{E F_{r} \times L E_{w e t}}{R_{n}-G}
\end{gathered}
$$

By utilizing similarity theory, a distinction is made in SEBS between the PBL/Atmospheric Boundary Layer (ABL) and the Atmospheric Surface Layer (ASL). Such distinction is made to take the ABL height as a reference of potential air temperature to calculate the heat fluxes. Here a distinction is made between surface temperature and potential air temperature. Remote sensing data-derived land parameters and ground-based meteorological measurements are used as inputs in SEBS. Using remote sensing data from ATSR and ground data from a Numerical Weather Prediction model, Jia et al. [81] proposed a modified version of SEBS and validated the estimated sensible heat flux with large aperture scintillometers. Wood et al. [82] applied SEBS to the Southern Great Plains region of the United States and compared the latent heat fluxes with the measurements from the Energy Balance Bowen Ration (EBBR) sites. Their results indicate the potential usefulness of SEBS approach in estimating surface heat flux from space for data assimilation purposes. Daily, monthly, and annual estimation of evaporation in a semi-arid environment have been done by SEBS [79]. SEBS can be even used for both local scaling and regional scaling under all atmospheric stability regimes as shown by $\mathrm{Su}$ [77]. Accuracy of ET value estimated from SEBS could reach 10\%-15\% of that of in-situ measurements even when evaporative fraction ranged from 0.5 to 0.9 as shown by $\mathrm{Su}$ et al. [83].

Main advantages of the SEBS include: (1) consideration of the energy balance at the limiting cases, which minimizes the uncertainty involved in surface temperature or meteorological variables; (2) new formulation of the roughness height for heat transfer instead of using constant values; (3) characterizing actual turbulent heat fluxes without any prior knowledge; and (4) representativeness of parameters associated with surface resistance. Note that SEBS has been widely applied over large heterogeneous areas fed with MODIS data with thermal band information of $1 \mathrm{~km}[15,84]$. However, relatively complex solution of the turbulent heat fluxes and too many required parameters can often cause more or less inconveniences in SEBS when data are not readily available.

\subsection{Simplified Surface Energy Balance Index (S-SEBI)}

A simplified new method derived from SEBI, called Simplified Surface Energy Balance Index (S-SEBI), has been developed to estimate the surface flux from remote sensing data [85]. Contrast between a reflectance (albedo) dependent maximum and minimum surface temperature for dry and wet conditions, respectively, is a main base of this method to partition available energy into sensible and latent heat fluxes. No additional meteorological data is needed if the surface extremes are available on 
the scene studied. By assuming steady global radiation and air temperature, a physical explanation to the observed surface reflectance and temperature in the S-SEBI approach can be given when surface characteristics within the observed image changes between dark/wet and dry/bright pixels. At low reflectance, surface temperature remains almost constant with increasing reflectance because of the presence of sufficient water under these conditions. At higher reflectance, surface temperature increases to some value with the increase of reflectance and is designated as "evaporation controlled" because of the fact that the change in temperature at this stage is solely controlled by the decrease of evaporation resulting from the less soil moisture availability. Beyond the inflexion of reflectance, the surface temperature declines with the increase of surface reflectance. At this point, soil moisture shrinks to such a level that evaporation cannot occur. Therefore, the available energy is completely utilized for surface heating. Thus, an increase in surface reflectance yields a net radiation decrease, which in turn produces less surface heating and the corresponding surface temperature, which is referred as "radiation controlled" $[63,85,86]$ (Figure 2). Here, evaporative fraction (EF) is constrained by the dry and wet regions and formulated by interpolating the reflection-dependent surface temperature between the reflection-dependent maximum and minimum surface temperatures as shown in Equation (15):

$$
E F=\frac{\left(T_{H}-T_{S}\right)}{\left(T_{H}-T_{L E}\right)}
$$

where $T_{H}$ is the land surface temperature corresponding to dry condition and represents the minimum latent heat flux $\left(L E_{d r y}=0\right)$ and maximum sensible heat flux $\left(H_{d r y}=R_{n}-G\right)$, and $T_{L E}$ is the land surface temperature corresponding to wet condition and represents the maximum latent heat flux $\left(L E_{\text {wet }}=\left(R_{n}-G\right)\right)$ and minimum sensible heat flux $\left(H_{\text {wet }}=0\right)$ for a given surface reflectance as shown in Figure 2.

Figure 2. Schematic relationship between surface temperature $v s$. surface reflectance in the S-SEBI (after Li et al. [63], Roerink et al. [85], Liou et al. [86]).

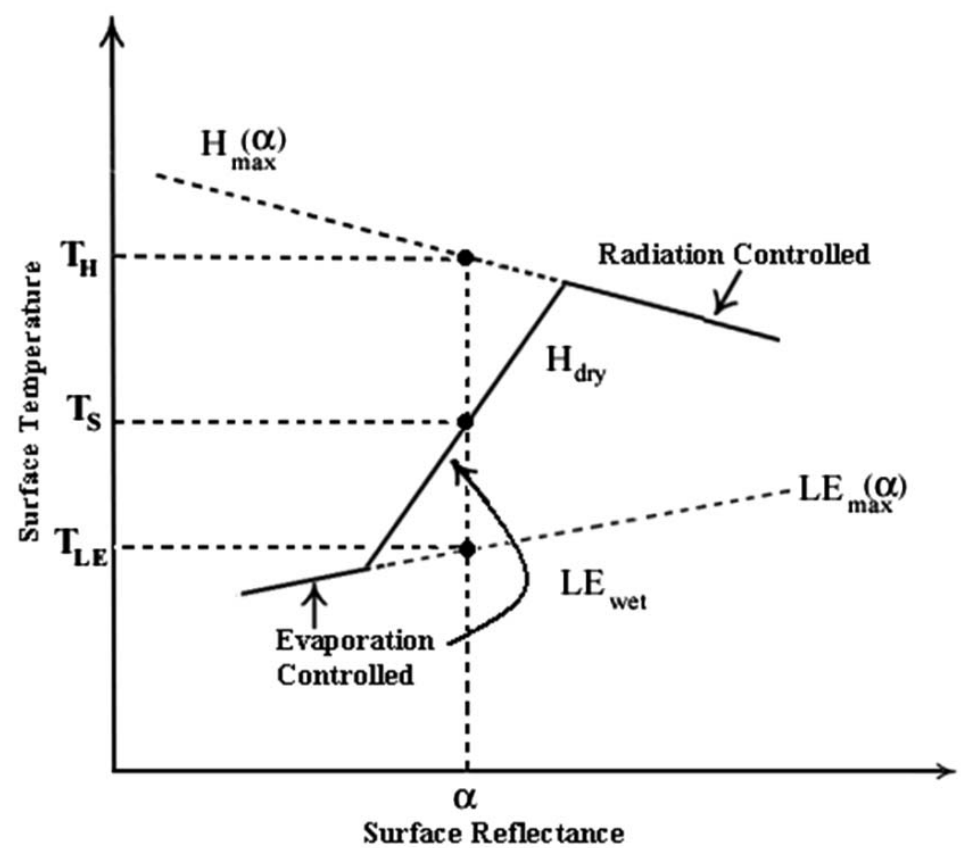


Using the following regression equation, $T_{H}$ and $T_{L E}$ can be, respectively, calculated:

$$
\begin{gathered}
T_{H}=c_{\text {max }}+d_{\text {max }} \alpha \\
T_{L E}=c_{\text {min }}+d_{\text {min }} \alpha
\end{gathered}
$$

where the empirical coefficients $c_{\max }, d_{\max }, c_{\min }$, and $d_{\min }$ are estimated from the scatter plot of $T_{s}$ and $\alpha$ over the study area. Finally, the EF is calculated from Equation (15) using Equations (16) and (17).

The major advantages of S-SEBI are that (1) Additional ground-based measurement is not needed to derive the EF except the surface temperature and reflectance (albedo) derived from remote sensing data if the surface extremes are present in the remotely sensed imagery; and (2) Extreme temperatures for the wet and dry conditions vary with changing reflectance (albedo) values, but in other methods like SEBAL, a fixed temperature is determined for wet and dry conditions.

\subsection{Surface Energy Balance Algorithm for Land (SEBAL)}

Surface Energy Balance Algorithm for Land (SEBAL), an image-processing model for calculating evapotranspiration (ET) as a residual of the surface energy balance, was developed in the Netherlands by Bastiaanssen et al. [87,88]. Within the most promising approaches currently available to estimate evapotranspiration, the SEBAL has been designed to calculate the energy balance components, at both local and regional scales with minimum ground data. This model is an intermediate approach using both empirical relationships and physical parameterization. It requires digital imagery data collected by any satellite sensor measuring visible, near-infrared, and thermal infrared radiation, $T_{s}, N D V I$, and albedo maps. Latent heat flux $(L E)$ is estimated as a residual of the energy balance equation on a pixel-by-pixel basis. Net radiation $\left(R_{n}\right)$ is computed from the balance of short and longwave radiation. Soil heat flux $(G)$ is calculated utilizing the equation proposed by Bastiaanssen, which is applicable to all sorts of vegetation cover and soil type [87,88]. Under several climatic conditions, this method has been verified at both field and catchment scales with typical accuracy at field scale being $85 \%$ and $95 \%$ at daily and seasonal scales, respectively, in more than 30 countries worldwide [89,90]. The estimation of sensible heat flux $(H)$ is required to obtain the parameters that will allow the computation of ET as a residual from the energy balance. In SEBAL, two reference air temperatures are taken. One being an air temperature located at height $h_{1}$ close to the surface and the other at an upper height $h_{2}$. To determine the value of $d T$ for each pixel, SEBAL assumes the existence of a linear relationship between $d T$ and the radiometric surface temperature $T_{s}$ considering homogeneous metrological and surface conditions:

$$
\mathrm{d} T=c T_{s}+d
$$

where $\mathrm{d} T$ is the near-surface air temperature difference, $T_{s}$ is the radiometric surface temperature, and " $c$ " and " $d$ " are empirical coefficients obtained from the so-called "anchor" pixels [91] for a given satellite image. Generally, the anchor pixels within the image represent conditions of extreme evaporative behavior. Evaporation is assumed to be consuming most of the available energy $\left(R_{n}-G\right)$ at a "wet (cold)" pixel, which indicates that the sensible heat flux $(H)$, and consequently $\mathrm{d} T$ are both assumed to be near zero $\left(\mathrm{d} T_{\text {wet }}=0\right)$. At a "dry (hot)" pixel where evaporation is near zero, all the 
available energy is modified essentially into sensible heat. Near surface air-temperature difference, $\mathrm{d} T$, is then computed using aerodynamic theory for the two extreme conditions [91] as:

$$
\mathrm{d} T_{d r y}=\frac{H_{d r y} \times r_{a d r y}}{\rho_{a i r d r y} C_{p}}
$$

where $H_{d r y}$ (sensible heat flux at dry limit $\left.\mathrm{W} \cdot \mathrm{m}^{-2}\right)$ and is equal to $\left(R_{n}-G\right)$.

Once the surface-air temperature differences at both dry (hot) and wet (cold) points are determined, coefficients " $c$ " and " $d$ " in Equation (18) can be easily estimated. By using " $c$ " and " $d$ ", the surface-air temperature difference $\mathrm{d} T$ at each pixel is calculated with $T_{s}$ using Equation (18). In SEBAL, the cold pixel is generally taken from a pixel located in deep water, and the hot pixel is taken from a pixel located in an area that shows high surface temperature.

Finally, $H$ is obtained iteratively with $r_{a} d r y$ corrected for stability using Equation (6). An extrapolation of wind speed from ground level to a height of about 100 to $200 \mathrm{~m}$ is required in this procedure. Identifying the dry pixels is the most important aspect in SEBAL, while the wet pixels are frequently spotted at a location of well watered areas or over a relatively large, calm water surface. However, a recent study [92] indicates that the SEBAL model tends to be context-dependent, i.e., wet/dry pixels (edges) required to trigger SEBAL may not necessarily exist within a specific extent of an image.

The major advantages of SEBAL for the estimation of land surface fluxes from thermal remote sensing data are (1) minimum use of auxiliary ground-based data; (2) automatic internal correction, which prevents strict correction of atmospheric effects on surface temperature; and (3) internal calibration, which is done within each analyzed image. Besides its several advantages, it has several drawbacks as well. Major disadvantages of this method are that (1) Subjective specifications of representative hot/dry and wet/cool pixels within the image are required [92,93] to determine model parameters $a$ and $b$. The resulting $H$ flux and ET estimates from SEBAL can vary with differing extreme pixels selected by the operator, domain size, and spatial resolution of satellite sensors [94]; (2) Over mountainous regions, some adjustments are required based on a digital elevation model for $T_{s}$ and $u$ to account for the lapse rate [95,96]; (3) Estimated $H$ is greatly affected by the errors in surface-air temperature differences or surface temperatures measurements; and (4) Ignoring the effect of radiometer viewing angle, can cause variation in $T_{s}$ by several degrees for some images.

\subsection{Mapping Evapotranspiration at High Resolution and with Internalized Calibration (METRIC)}

Mapping evapotranspiration at high Resolution with Internalized Calibration (METRIC) is a variant of SEBAL, an energy balance model developed in The Netherlands. It is also an image-processing tool for mapping regional ET over more complicated surfaces as a residual of the energy balance at the Earth's surface. METRIC has been extended from SEBAL through integration with reference ET, which is computed using ground-based weather data. The fundamental principle underlying METRIC is that evaporating liquid drops absorbs heat as indicated by Allen et al. [97,98] to derive ET from remotely sensed data in visible, near-infrared, and thermal infrared spectral regions along with ground-based measurements of wind speed and near-surface dew point temperature. Two anchor conditions are selected within an observed scene to internally calibrate the sensible and latent heat flux 
computation and to fix boundary conditions for the energy balance. Such internal calibration eliminates the need for an in-depth atmospheric correction of surface temperature or reflectance (albedo) measurements using the radiative transfer model [99]. The internal calibration, similar to SEBAL, also reduces impacts of any biases in estimation of aerodynamic stability correction or surface roughness. The calibration is done by choosing manually a hot and a cold pixel to define the range of vertical temperature gradients $(d T)$ above the surface. The cold condition is typically a well-irrigated alfalfa field where $E T=E T r$ (reference $E T$ over the standardized $0.5 \mathrm{~m}$ tall alfalfa in $\mathrm{mm} / \mathrm{h}$ ). The hot condition is typically a dry bare agricultural field where $E T=0$. Once surface temperature, $T_{s}$, and $\mathrm{d} T$ are calculated corresponding to hot and cold conditions, the linear relationship as indicated in Equation (18) is defined. However, the context-dependency of SEBAL, METRIC, and triangular models has been indicated in a recently conducted study [92]. They indicated that the wet/dry pixels (edges) required to trigger these models may not necessarily exist within a specific extent of an image. As the extent of satellite image and/or spatial resolution of satellite vary, the wet/dry limits of ET could change significantly, thereby resulting in differing model outputs, i.e., the ET estimates from these models are not deterministic. It is unknown, particularly in SEBAL, exactly how large extent of a study site of interest would be appropriate for the operator to properly select the so-called hot/wet pixels that can satisfy the assumptions made in these models so that the linear correlation between the near surface temperature difference and remotely sensed surface temperature holds true. In many cases, even the very large extent would not necessitate the existence of both hot and wet extremes. For instance, one would not be able to select a hot pixel from a large homogeneous forest. Also, there is no other alternative for the SEBAL/METRIC models to automatic selection of extreme pixels from images with varying extents, spatial resolutions, and clouds [94,100], Furthermore, even though the extremes can be properly selected from relatively large images that probably entail hot and cold extremes reflecting surface conditions after cloud and terrain effects are favorably reduced/removed, the SEBAL-type algorithms appear to be limited in providing reasonable ET patterns due mostly to constant coefficients " $c$ " and " $d$ " in the SEBAL algorithm that do not accommodate the effect of variations in fractional vegetation cover on ET extremes [92,93].

The performance of the METRIC model has been tested by Gowda et al. [60] in the Texas High Plains on two different days in 2005 using Landsat 5 TM data by comparison of resultant daily ET estimates with measured values derived from soil moisture budget. Integration of water balance model with METRIC estimated ET could provide significant improvements in the irrigation schedules as found in Spain by Santos et al. [101]. Tasumi et al. [99] pointed out the high potential for successful ET estimates of SEBAL/METRIC models by comparing the derived ET with lysimeter measured values in the semi-arid US.

\subsection{Two-Source Models (TSM)}

Norman et al. [102] proposed a new model named two-source model, also known as duel-source model to improve the accuracy of LE estimates using satellite remote sensing data, especially over sparse surfaces [102-106]. The basic principle of this model is to partitioning the composite radiometric surface temperature into soil and vegetation components, and considered sensible and latent heat fluxes are transferred to the atmosphere from both surface components. Dispensability of 
ground-based information or any priori calibration has made the applicability of duel source model wider without resorting to any additional input data. In the duel source model, satellite-derived surface temperature $\left(T_{S}\right)$ is considered to be a composition of the soil $\left(T_{\text {soil }}\right)$ and canopy temperatures $\left(T_{v e g}\right)$, and $H$ and $L E$ are also divided into soil and vegetation contributions, respectively. Canopy latent heat flux is computed using the Priestley-Taylor equation [107]. An iterative method is used to obtain the soil $\left(T_{\text {soil }}\right)$ and canopy temperatures $\left(T_{\text {veg }}\right)$ from satellite-derived $T_{s}$ setting an initial value of 1.3 for the Priestley-Taylor parameter $\alpha[108,109]$. This nominal choice of $\alpha$ overestimates canopy latent heat flux under moisture-stressed conditions and yield negative soil evaporation $\left(L E_{\text {soil }}\right)$ and is regarded as a nonphysical solution during the daytime. The $\alpha$ is therefore iteratively reduced until $L E_{\text {soil }}$ approaches zero to obtain a final $\alpha$ as well as $T_{\text {soil }}$ and $T_{\text {veg. }}$. The $L E$ and $H$ are then calculated from these estimates. Both the one- and Two-source models are sensitive to their use of the temperature differences to estimate $H$. Dispensability of precise atmospheric corrections, emissivity estimations and high accuracy in sensor calibration are the main advantages of the duel source method. Coupling of the duel source models with PBL eliminates the need of ground-based measurement of $T_{a}$ [55] and, thus, is much better suitable to applications over large-scale regions than other algorithms [110]. Effects of view geometry are normally incorporated, while the empirical corrections for the "excess resistance" are eliminated in the duel-source models. More details of these Two-source models are found in Li et al. [63], while the revision and recent advancements of these Two-source models are found in the literature [62,63,111-117].

\section{Distinction between SEBAL and METRIC}

Distinctions between SEBAL and METRIC are summarized here:

(1) At wet pixel, METRIC does not assume $H_{\text {wet }}=0$ or $L E_{\text {wet }}=\left(R_{n}-G\right)$. Instead, a daily surface soil water balance is used to assure that ET is zero and set to $1.05 E T r$ at hot and wet pixels, respectively. ETr is the hourly tall reference (like alfalfa) ET calculated using the standardized ASCE Penman- Monteith equation;

(2) In METRIC, wet pixels are selected in an agricultural setting, while on the other hand the cold pixels are selected based on biophysical characteristics similar to the reference crop (like alfalfa); and

(3) Instead of the actual evaporative fraction, the interpolation (extrapolation) of instantaneous ET to daily value is based on the alfalfa $E \operatorname{Tr} F$ (ratio of instantaneous $E T$ to the reference $E T r$ and is computed from meteorological station data at satellite overpass time).

Comparisons of the different remote sensing ET models reviewed above are summarized in Table 1 for quick reference. 
Table 1. Comparisons of the different remote sensing ET models.

\begin{tabular}{|c|c|c|c|c|}
\hline Algorithms & $\begin{array}{l}\text { Input } \\
\text { Parameters }\end{array}$ & Main assumptions & Merits & Demerits \\
\hline SEBI & $\begin{array}{l}<T>_{p b l}, h_{p b l}, v, \\
T_{s}, R_{n}, G \\
\end{array}$ & $\begin{array}{l}(\mathrm{ET})_{d r y} \text { limit }=0 \\
(\mathrm{ET})_{\text {wet limit }} \rightarrow \text { evaporates potentially }\end{array}$ & $\begin{array}{l}\text { Relating the effects of } T_{s} \text { and } r_{a} \\
\text { directly on LE }\end{array}$ & $\begin{array}{l}\text { Requires ground based } \\
\text { measurements }\end{array}$ \\
\hline SEBS & $\begin{array}{l}T_{\text {air }}, h_{a}, v \\
T_{s}, R_{n}, G\end{array}$ & $\begin{array}{l}(E T)_{d r y ~ l i m i t}=0 \\
(E T)_{\text {wet limit }} \rightarrow \text { takes place at a } \\
\text { potential rate }\end{array}$ & $\begin{array}{l}\text { Uncertainty in SEBS from } T_{s} \\
\text { and meteorological parameters } \\
\text { can partially be solved; } \\
\text { Roughness height for heat } \\
\text { transfer is computed explicitly } \\
\text { instead of using fixed values }\end{array}$ & $\begin{array}{l}\text { Requires too many } \\
\text { parameters; } \\
\text { Relatively complex } \\
\text { derivation of turbulent } \\
\text { heat fluxes }\end{array}$ \\
\hline S-SEBI & $T_{s}, \alpha_{s}, R_{n}, G$ & $\begin{array}{l}(E F)_{\alpha}=\left(T_{H}-T_{S}\right) /\left(T_{H}-T_{L E}\right) \\
T_{H}=(L E)_{\min } \\
T_{L E}=(L E)_{\max }\end{array}$ & $\begin{array}{l}\text { Ground based measurements } \\
\text { are not required }\end{array}$ & $\begin{array}{l}\text { Extreme temperatures } \\
\text { are location specific }\end{array}$ \\
\hline SEBAL & $\begin{array}{l}v, h_{a}, \\
T_{s}, V I, R_{n}, G\end{array}$ & $\begin{array}{l}\mathrm{d} T=c T_{s}+d \\
(E T)_{\text {dry pixel }}=0 \\
(E T)_{\text {wet }} \rightarrow \text { considered as the surface } \\
\text { available energy }\end{array}$ & $\begin{array}{l}\text { Requires minimum Ground } \\
\text { based measurements; } \\
\text { Equipped with automatic } \\
\text { internal calibration; } \\
\text { Exact atmospheric corrections } \\
\text { are not required }\end{array}$ & $\begin{array}{l}\text { Applied over } \\
\text { plain surfaces; } \\
\text { Possesses uncertainties } \\
\text { in the determination of } \\
\text { anchor pixels }\end{array}$ \\
\hline METRIC & $\begin{array}{l}v, h_{a} \\
T_{s}, V I, R_{n}, G\end{array}$ & $\begin{array}{l}(E T)_{\text {hot pixel }}=0 \\
(L E)_{\text {wet pixel }}=1.05 E T r\end{array}$ & $\begin{array}{l}\text { Similar to SEBAL, but surface } \\
\text { slope and aspect can be } \\
\text { considered }\end{array}$ & $\begin{array}{l}\text { Possesses uncertainties } \\
\text { in the determination of } \\
\text { anchor pixels }\end{array}$ \\
\hline TSM & $\begin{array}{l}v, h_{a}, T_{a i r} \\
T_{s}, T_{c}, F_{r} \text { or } \\
L A I, R_{n}, G\end{array}$ & $\begin{array}{l}\text { (1) Component fluxes are parallel to } \\
\text { each other; } \\
\text { (2) Priestly-Taylor equation is used } \\
\text { to compute canopy transpiration. }\end{array}$ & $\begin{array}{l}\text { (1) Includes the view geometry; } \\
\text { (2) Eliminates the need of } \\
\text { empirical corrections for } \\
\text { the "excess resistance". }\end{array}$ & $\begin{array}{l}\text { (1) Many ground } \\
\text { measurements and } \\
\text { components are } \\
\text { needed. }\end{array}$ \\
\hline
\end{tabular}

Abbreviations: $\langle T\rangle_{p b l}=$ Average planetary boundary layer temperature; $h_{p b l}=$ Height of the PBL; $v=$ Wind speed; $T_{s}=$ Surface temperature; $T_{c}=$ Vegetation canopy temperature; $R_{n}=$ Surface net radiation; $G=$ Soil heat flux density; $h_{a}=$ Measurement height of wind speed and air temperature; $V I=$ Vegetation Index; $L A I=$ Leaf Area Index; $F_{r}=$ Fractional vegetation cover; $\alpha_{s}=$ Surface shortwave albedo; $T_{\text {air }}=$ Air temperature measured at a reference height.

\section{Uncertainties Associated with ET Retrieval from Remote Sensing}

\subsection{Problems Associated with Surface Temperature Obtained from Remote Sensing}

Most of the remote sensing methods that are adopted to derive surface temperature use Thermal Infrared (TIR) radiation data. Surface emissivity and atmospheric corrections affect the retrieval of surface temperature and thus affect the quality of the information extracted from remote measurements. Two surface temperature correction methods, namely direct and indirect methods, may be applied. The direct method uses atmospheric sounding combined with the radiative transfer model, while the indirect method uses only satellite observations. Improved estimation is reached by Duel angle Along Track Scanning Radiometer (ATSR) observation, which is capable of performing two nearly simultaneous measurements of brightness temperature from two different view angels. 
Atmospheric correction leads to typical uncertainties of about 1-3 K. Emissivity is the other crucial parameter, which can lead to significant error. One of the most promising ways for obtaining both surface directional infrared temperature and emissivity is based on high spectral resolution [118], which can reduce the error to some extent.

\subsection{Limitations of Satellite Coverage Uncertainties in Remotely Sensed Data}

Different spatial and temporal scale ETs at regional and global scales are needed for many relevant disciplines. However, simultaneous acquiring of high temporal and spatial resolution imagery is very tough as satellites providing high spatial resolution imagery usually possess lower temporal frequency and vise versa. Clouds creates impediments in acquiring incessant satellite imagery and land surface parameters making the TIR method biased towards clear sky conditions. Larger time in acquiring the satellite imagery and ET estimation can make the method impractical in operational applications. Gap filling procedures $[29,119]$ and coupling models [120] have shown some promises to resolve this issue.

\subsection{Uncertainties in Solar Parameters Estimation}

Estimation of the individual components of the available energy $\left(R_{n}-G\right)$ leads to errors in the estimation of both short and long-wave components and ignores diurnal variation and phase difference between the diurnal cycles of each component. Moreover, differentiation has not been made between direct and diffuse radiation and total $R_{n}$ flux is only considered in most SEB models, but not the relative fractions of diffuse and direct radiation. The effects of increased diffuse radiation need to be considered because of its bulk use in vegetation than direct radiation [121]. A significant difference in ET estimation is therefore highly expected if such differences in water use efficiency are neglected.

\subsection{Uncertainties in Land Surface Variables}

Uncertainties in the radiance measurement caused by atmosphere require the corrections for the atmospheric effects. Despite sufficient progress, accuracy of some land surface variables (parameters) from remotely sensed data, such as surface temperature, LAI, vegetative coverage, plant height, etc., still needs to be improved in order to improve ultimately the accuracy of ET estimation. Temporal and spatial observations of air temperature and its spatial representativeness introduce uncertainties in ET estimation in some methods, which use $\left(T_{\text {aero }}-T_{\text {air }}\right)$. Wind speed and aerodynamic surface characteristics pose a major challenge. Aerodynamic resistance $\left(r_{a}\right)$ estimation requires stability corrections as well as suitable values for roughness lengths and zero displacement level. Compared to homogeneous dense and well-watered vegetative surfaces, the observational angular effect is more prominent and crucial over heterogeneous surfaces in retrieving the surface temperature [118]. Differences in received radiances will occur due to the differing amounts of soil and vegetation in the field of view when sensor viewing changes from one angle to another $[110,122]$.

\subsection{Inconsistency in Remote Sensing ET Models}

Different models are used for different land surface characteristics. However, till date, there is no universal model, which could be used throughout the world irrespective of the changes in land surface 
characteristics, in the climate and terrain without any modification or improvement to estimate the ET from satellite data.

\subsection{Inadequate Near-Surface Meteorological Variables Measurements}

Meteorological data at PBL-height or at near-surface height are frequently needed in most of the ET models and are obtained at a satellite pixel by spatial interpolation method using local meteorological stations data. Because of big differences in climate and terrain conditions in the study region and sparse/irregular presence of meteorological stations, accuracy of the interpolation method needs to be improved.

\subsection{Limitations of Empirical Vegetation Index Models}

The empirical vegetation index model is limited to the regions where net radiation is a major controlling factor and where large scale advection is not important [123] and useful at time scales of weeks to years, but is unable to capture $E$ at time scales of days or shorter [59]. "Such time series studies may be confounded by spurious autocorrelations if $E$ and vegetation index independently follow the same seasonal trend" [59].

\subsection{Nocturnal Transpiration and Dew}

Nocturnal transpiration and dew may also affect significantly the ET estimation. Nocturnal transpiration has been widely observed using sap-flow and gas exchange measurements with ratios of night-time to day-time transpiration as large as $25 \%$ being reported [124]. If nocturnal transpiration occurs at sites with high LAI, this process could be an important source of error in remote sensing based ET estimation because of its association with nocturnal vapor pressure difference and wind speed. Adversely, at sites with low LAI, this process will tend to reduce this source of error so that it may be ignored when considering daily TIR-based estimates of ET. Pinter [125] showed that early-morning dew on the vegetation surface may affect the remotely sensed radiant temperature and ultimately the ET estimation if the vegetation was not well-watered. This potential impact would be greater for satellite data acquired mid-morning (e.g., Landsat) compared to those commonly acquired mid-afternoon (e.g., AVHRR). Recent studies indicate that impact of dew on early-morning passive microwave [126] and reflective data [125,127] also needs to be accounted.

Besides the above mentioned issues, other limitations or uncertainties in remote sensing measurements like spatial and temporal scaling effects, lack of the land surface ET at satellite pixel scale for the truth validation have been described in details in the literature $[62,63]$.

\section{Results and Discussion}

Liou et al. [86] studied the S-SEBI model to estimate evapotranspiration over a rice paddy in Taiwan, and their results showed that the accuracy was not satisfactory. In this paper results obtained from a method $[22,86]$ similar to S-SEBI and based on the surface energy balance with atmospheric correction using airborne high-resolution multi-spectral images in conjunction with the surface meteorological data is presented to determine the evapotranspiration on a rice paddy. In this method, 
atmospheric correction has been achieved through a numerical iteration method by using the Monin-Obukhov length as the threshold of convergence. When convergence is reached, the evaporative fraction has been derived from the scatter plot of surface albedo versus temperature $[63,85,86]$. In addition, the sensible heat and latent heat fluxes have been redistributed by the evaporative fraction determined by radiation and evaporation controlled lines. However, in order to find a suitable evaporation fraction, four different covers have been tested as ground control points and compared with in-situ eddy covariance. The results presented in Figures 3 and 4 show that the auto selected ground controls, determination of ground control points by using the maximum and minimum value, is the best method and, therefore, is used to retrieve the regional latent heat flux (evapotranspiration) over a rice paddy. These results, with a bias of evaporation fraction of $6.3 \%$, are better compared with the results of SEBAL using in-situ data.

Figure 3. Sensible heat and latent heat fluxes over rice paddy field derived by the proposed method $[22,86]$.
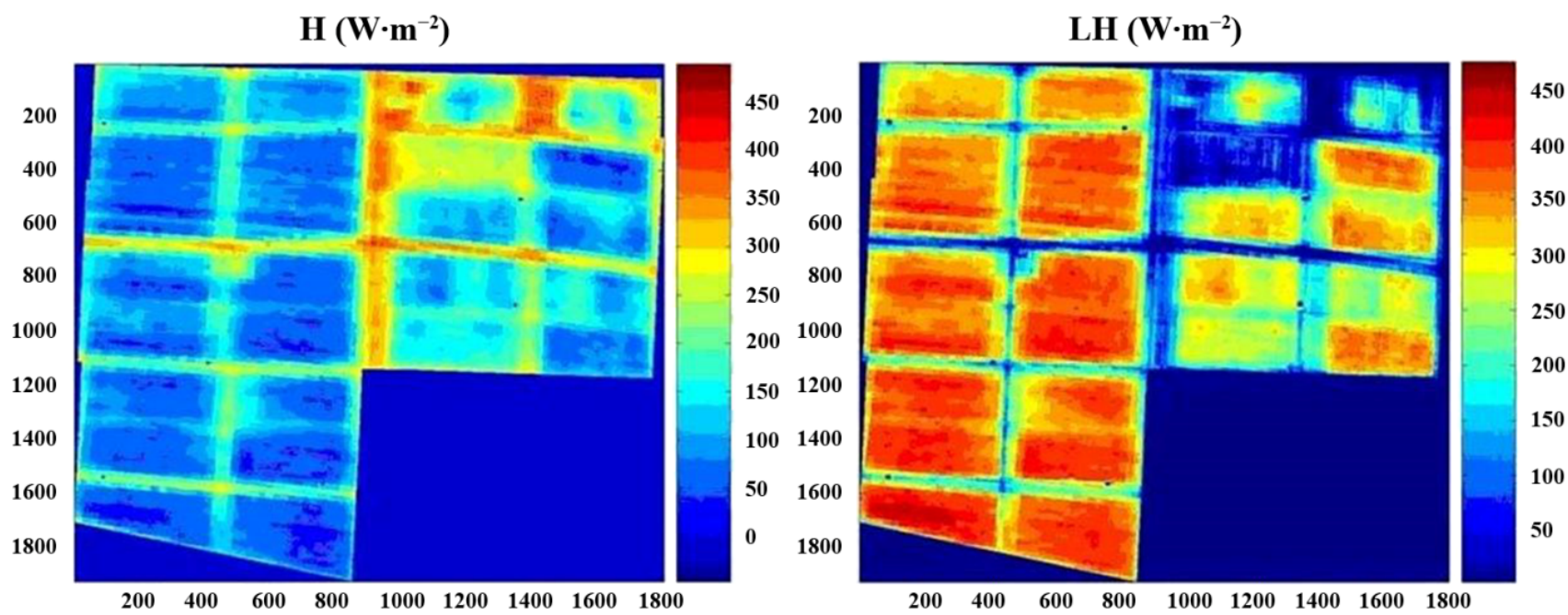

Figure 4. Relationship of latent heat fluxes retrieved from MODIS and in-situ eddy covariance data.

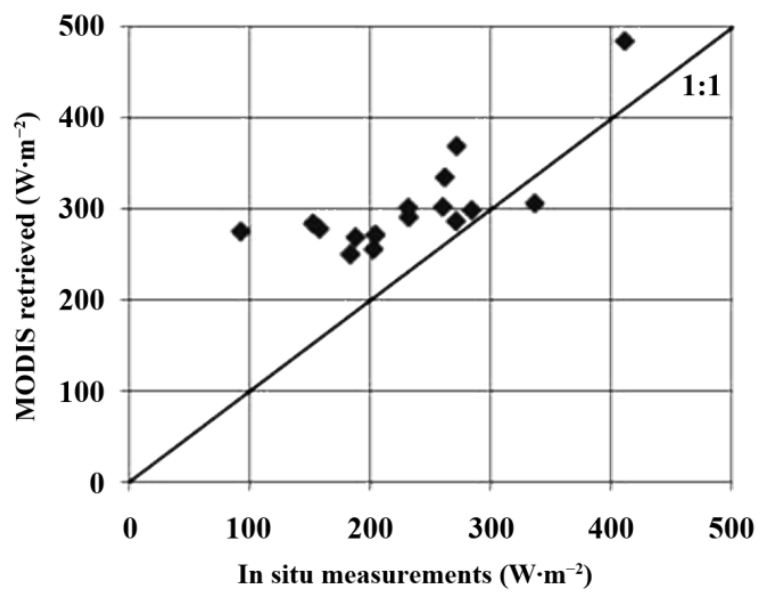

In order to assess the feasibility of monitoring long-term evapotranspiration with the developed model, relatively low-resolution satellite images, such as several MODIS Level 1B data, have been used. 
Derivative products of the MODIS sensor, such as MODIS/Aqua Land Surface Temperature/Emissivity Daily L3 Global 1km SIN Grid (MYD11A1), MODIS/Aqua Surface Reflectance Daily L2G Global 250m SIN Grid (MYD09GQK), MODIS/Aqua Vegetation Indices 16-Day L3 Global 1km SIN Grid (MYD13A2), MODIS/Aqua Leaf Area Index/FPAR 8-day L4 Global 1km SIN Grid (MYD15A2) from USGS/NASA, have also been used for comparative study. Input parameter products, which were calculated from Level 1B images demonstrated better results compared to the derivative products from USGS/NASA. Firstly, the derivative MODIS parameter products from USGS and auto-calculating parameter products by the MODIS Level 1B images have been used to study the surface heat fluxes of rice agricultural cycles and to test the convenience and accuracy of the results. It shows that the auto-calculating parameters produced by MODIS Level 1B images are better than derivative MODIS products, with the biases of latent heat flux of $61.10\left(\mathrm{~W} \cdot \mathrm{m}^{-2}\right)$ and sensible heat flux of $-57.97\left(\mathrm{~W} \cdot \mathrm{m}^{-2}\right)$. Finally, combining raw MODIS images in 2006 with the method to retrieve surface heat fluxes are performed, and the correlation coefficients of latent heat flux and sensible heat flux with corresponding in-situ observations are over 0.60 .

\section{Conclusions and Future Prospects}

From the present review of all the algorithms, it is seen that each algorithm has its own advantages and disadvantages. Nevertheless, despite their advantages and disadvantages, these algorithms are important tools for evapotranspiartion estimation on a regional scale. Except the parameters of the surface temperature and reflectance (albedo), no additional ground-based measurement is needed in the S-SEBI algorithm if the surface extremes are present in the remotely sensed imagery. The extreme temperatures vary with reflectance change for the wet and dry conditions, while in other methods like SEBAL it is required to determine a constant temperature for wet and dry conditions. The SEBAL also has several advantages like minimum auxiliary ground-based data, automatic internal calibration within each analyzed image. However, the accuracy of ET estimation obtained from these methods varies from one model to another and from one temporal and spatial scale to another. Accuracy of ET value estimated from SEBS could reach $10 \%-15 \%$ of ET estimation obtained from in-situ measurements even when evaporative fraction ranged from 0.5 to 0.9 as has been reported by $\mathrm{Su}$ et al. [83]. A maximum relative difference of $8 \%$ between the measured and estimated evaporative fraction values have been reported when measurements were compared with the S-SEBI derived outputs by Roerink et al. [85]. Accuracy for the daily evapotranspiration using the S-SEBI method has been found to be lower than $1 \mathrm{~mm} / \mathrm{d}$ [128]. Sobrino et al. [129] reported a RMSE of $1.4 \mathrm{~mm} / \mathrm{d}$ in the ET estimation when results derived from S-SEBI were checked against the high resolution ET values. Under several climatic conditions, SEBAL has been tested with the typical accuracy at a field scale being $85 \%$ and $95 \%$ at daily and seasonal scales, respectively $[89,90]$. The SEBAL model has been widely used to estimate ET across a variety of climates, ecosystems, and land covers (primarily for consumptive water use by agricultural crops). This model enriched TIR remote sensing-based approaches that also include triangular approaches [130,131], two-source energy balance approaches [44,102], and the other one-source approaches [77]. However, application of SEBAL by Trezza [132] for a variety of crops in Kimberly, ID resulted in ET estimation errors ranging from 2.7\% to $35 \%$ with an average error of $18.2 \%$, while the results presented from our present study show a bias 
of evaporation fraction of $6.3 \%$ compared with the results of SEBAL using in-situ eddy covariance data. Moreover, over mountainous areas, SEBAL shows some limitations [95,96]. These limitations are solved in the METRIC model. From the above review, it is found that SEBAL/METRIC models had high potential for successful ET estimates in the semi-arid US by comparing the derived ET with lysimeter observations [99]. Nevertheless, in the recently conducted study, the context-dependency of SEBAL, METRIC, and triangular models has been noticed [92], which has already been discussed in details in earlier section. Although the reviewed methods show an enough potential and viability for evapotranspiartion estimation on a regional scale, these methods have several drawbacks as well, which limit their applicability and accuracy to some extent. Also, the method $[22,86]$, mentioned here, is not free from all these limitations. Careful calculation or geospatial technique can further enhance the radio geometry, and the ground truth data of the presented method. Therefore, new innovated methods in acquisition of remotely sensed data and meteorological variables or newly-developed ET models are required to solve the addressed limitations. The main restricting factors in the estimates of instantaneous ET or daily, weekly, and monthly values, over a regional scale from remote sensing techniques are retrieval accuracy, physical interpretation of different surface variables, parameterization of regional land surface fluxes, temporal and spatial data/model scaling among various scales, validation of model generated latent heat flux at regional scale, and acquisition of near-surface meteorological data over various satellite pixel scales.

LST is one of the most critical factors affecting the accuracy of the ET estimates. It directly indicates how much energy and water may be available over the land surface. LST and other allied surface variables like surface albedo, soil moisture, emissivity, fractional vegetation cover, $N D V I$, and $L A I$ affect the precise partition of energy components significantly and consequently the accuracy of the retrieved regional ET. Despite considerable progress in the quantitative retrieval of the land surface variables from remote sensing data [65,133-135], the accuracy of some surface variables, essential in remote sensing ET algorithms, still needs to be improved. Therefore, special attention must be given to the physical interpretation of these surface variables retrieved directly or indirectly from satellite data.

Although remote sensing ET models can provide relatively accurate spatial distributions of instantaneous ET, it is usually only employed under clear sky conditions and at an instantaneous scale. On the other hand, land surface process models are suitable for simulating long-term development trend of the soil water content, turbulent heat fluxes, and other related processes [136,137]. However, it is worth mentioning that due to low spatial resolution and uncertainties in the model inputs, it is sometimes impossible to estimate correctly the latent heat flux with land surface process models at a large scale without additional information obtained from satellite data. Therefore, integration of energy based land surface process models [136,137] may substantially improve the limitations of the current remote sensing ET algorithms. Moreover, data assimilation is supposed to be another effective way to estimate temporal and spatial ET continuously by integrating the models, data, and optimization methods together because of rapid improvement of multi-spectral, multi-spatial, and multi-temporal satellite technology, computer processing technique, and optimization algorithms. The link between remote sensing and distributed hydrological modelling will be vital for most future applications and possibly improve the possibilities for making a more spatially detailed evaluation.

Accuracy of the available energy at the land surface into turbulent fluxes is greatly affected by advection. It directly causes the imbalance of surface energy particularly over small spatial scales and 
enhances evaporation from the land surface. Our present understanding is limited on what scale advection will have to be considered and how energy exchange takes place between adjacent pixels in the horizontal direction. This issue must be addressed properly and further research is required to resolve this issue.

Among various problems in ET estimation, validation is one of the most troublesome problems, particularly because of both the scaling and the advection effects. Such issues may be resolved by developing various validation methods, which may include comparison of ET derived from remote sensing and ground-based measurements over same location, verification of ET derived from satellite data at different spatial resolution or obtained by integrating various data sources in land surface process models, and trend verification between remote sensing data and independently obtained reference data, which are either driven or constrained by ET or remotely sensed data. However, it is worth mentioning in this context that the validation of turbulent heat fluxes at a satellite pixel scale with the "point" scale measurements obtained with Bowen ratio, lysimeter or eddy correlation systems may again raise some questions because of surface heterogeneity and scaling effects.

\section{Acknowledgments}

We are thankful to the National Science Council (NSC) of Taiwan for financial support through grants No. NSC 102-2111-M-008-027, NSC 102-2221-E-008-034 and NSC 102-2111-M-008-027. We are also extremely grateful to the anonymous reviewers for their valuable critical comments, which helped us a lot improve the standard of the manuscript.

\section{Conflicts of Interest}

The authors declare no conflict of interest.

\section{References}

1. Wild, M.; Folini, D.; Schar, C.; Loeb, N.; Dutton, E.G.; Langlo, G.K. The global energy balance from a surface perspective. Clim. Dyn. 2013, 40, 3107-3134.

2. Stephens, G.L.; Li, J.L.; Wild, M.; Clayson, C.A.; Loeb, N.; Kato, S.; L’Ecuyer, T.; Stackhouse, P.W.; Andrews, T. The energy balance of the Earth's climate system. Nat. Geosci. 2012, 5, 691-696.

3. Kiehl, J.T.; Trenberth, K.E. Earth's annual global mean energy budget. Bull. Am. Meteorol. Soc. 1997, 78, 197-208.

4. Trenberth, K.E.; Fasullo, J.T. Tracking earth's energy: from El Nino to global warming. Surv. Geophys. 2012, 33, 413-426.

5. Wild, M.; Ohmura, A.; Gilgen, H.; Roeckner, E.; Giorgetta, M.; Morcrette, J.J. The disposition of radiative energy in the global climate system: GCM-calculated versus observational estimates. Clim. Dyn. 1998, 14, 853-869.

6. Wild, M. New directions: A facelift for the picture of the global energy balance. Atmos. Environ. 2012, 55, 366-367. 
7. Anderson, D.E.; Cahalan, R.F. The Solar Radiation and Climate Experiment (SORCE) mission for the NASA Earth Observing System (EOS). Sol. Phys. 2005, 230, 3-6.

8. Loeb, N.G.; Wielicki, B.A.; Doelling, D.R.; Smith, G.L.; Keyes, D.F.; Kato, S.; Manalo-Smith, N.; Wong, T. Toward optimal closure of the Earth's top-of-atmosphere radiation budget. J. Clim. 2009, 22, 748-766.

9. Kustas, W.P.; Jackson, T.J.; Prueger, J.H.; MacPherson, J.I.; Wolde, M. Effects of remote sensing pixel resolution on modelled energy flux variability of croplands in Iowa. Remote Sens. Environ. 2004, 92, 535-547.

10. Dodds, P.E.; Meyer, W.S.; Barton, A. A Review of Methods to Estimate Irrigated Reference Crop Evapotranspiration across Australia; Document prepared for Irrigation Features Technical Report, Australia, 2005. Available online: http://www.clw.csiro.au/publications/consultancy/ 2005/CRCIFtr04-05CropEvapotranspiration.pdf\#search=\%22A\%20review\%20of\%20methods\% 20 to $\% 20$ stimate $\% 20$ irrigated $\% 20$ reference $\% 20$ crop $\% 20$ evapotranspiration $\% 20$ across $\% 20$ Austra lia.\%20\%22 (accessed on 15 May 2009).

11. Consoli, S.; Urso, G.; Toscano, A. Remote sensing to estimate ET-fluxes and the performance of an irrigation district in southern Italy. Agric. Water Manag. 2006, 81, 295-314.

12. Liou, Y.-A.; Galantowicz, J.; England, A.W. A land surface process radiobrightness with coupled heat and moisture transport for prairie grassland. IEEE Trans. Geosci. Remote Sens. 1999, 37, 1848-1859.

13. Jacob, F.; Olioso, A.; Su, Z.; Sequin, B. Mapping surface fluxes using airborne visible, near infrared, thermal infrared remote sensing data and a spatialized surface energy balance model. Agronomie 2002, 22, 669-680.

14. Xu, C.Y.; Chen, D. Comparison of seven models for estimation of evapotranspiration and groundwater recharge using lysimeter measurement data in Germany. Hydrol. Process. 2005, 19, 3717-3734.

15. McCabe, M.F.; Wood, E.F. Scale influences on the remote estimation of evapotranspiration using multiple satellite sensors. Remote Sens. Environ. 2006, 105, 271-285.

16. Guo, H.; Hu, Q.; Jiang, T. Annual and seasonal stream flow responses to climate and land-cover changes in the Poyang Lake basin, China. J. Hydrol. 2008, 355, 106-122.

17. Liou, Y.-A.; Kim, E.J.; England, A.W. Radiobrightness of prairie soil and grassland during dry-down simulations. Radio Sci. 1998, 33, 259-265.

18. Liou, Y.-A.; England, A.W. A land-surface process radiobrightness model with coupled heat and moisture transport for freezing soils. IEEE Trans. Geosci. Remote Sens. 1998, 36, 669-677.

19. Liou, Y.-A.; England, A.W. A land surface process/radiobrightness model with coupled heat and moisture transport in soil. IEEE Trans. Geosci. Remote Sens. 1998, 36, 273-286.

20. Hernandez-Ramirez, G.; Jerry, L.H.; John, H.P.; Thomas, J.S. Energy balance and turbulent flux partitioning in a corn-soybean rotation in the Midwestern US. Theor. Appl. Climatol. 2010, 100, 79-92.

21. Verma, S.B.; Kim, J.; Clement, R.J. Momentum, water vapour, and carbon dioxide exchange at a centrally located prairie site during FIFE. J. Geophys. Res. 1992, 97, 8629-18639.

22. Chang, T.-Y.; Liou, Y.-A.; Lin, C.-Y.; Liu, C.-S.; Wang, Y.-C. Evaluation of surface heat fluxes in Chiayi plain of Taiwan by remotely sensed data. Int. J. Remote Sens. 2010, 31, 3885-3898. 
23. Blanken, P.D.; Black, T.A.; Neumann, H.H.; den Hartog, G.; Yang, P.C.; Nesic, Z.; Staebler, R.; Chen, W.; Lee, X. Turbulent flux measurements above and below the over story of a boreal aspen forest. Bound Lay. Meteorol. 1998, 89, 109-140.

24. Wang, Y.-C.; Chang, T.-Y.; Liou, Y.-A.; Ziegler, A. Terrain correction for increased estimation accuracy of evapotranspiration in a mountainous watershed. IEEE Geosci. Remote Sens. Lett. 2010, 7, 352-356.

25. Azevedo, P.V.; Silva, B.B.; da Silva, V.P.R. Water requirements of irrigated mango orchards in northeast Brazil. Agric. Water Manag. 2003, 58, 241-254.

26. Vilalolobos, F.J.; Testi, L.; Rizzalli, R.; Orgaz, F. Evapotranspiration and crop coefficients of irrigated garlic (Allium sativum L) in a semi-arid climate. Agric. Water Manag. 2004, 64, 233-249.

27. Yunusa, I.A.M.; Walker, R.R.; Lu, P. Evapotranspiration components from energy balance, sapflow and microlysimetry techniques for an irrigated vineyard in inland Australia. Agric. For. Meteorol. 2004, 127, 93-107.

28. Rana, G.; Katerji, N.; Lorenza, F.D. Measuring and modelling of evapotranspiration of irrigated citrus orchard under Mediterranean conditions. Agric. For. Meteorol. 2005, 128, 199-209.

29. Anderson, M.C.; Norman, J.M.; Mecikalski, J.R.; Otkin, J.A.; Kustas, W.P. A climatological study of evapotranspiration and moisture stress across the continental United States based on thermal remote sensing: 1. Model formulation. J. Geophys. Res. Atmos. 2007, 112, D10117.

30. Bastiaanssen, W.G.M.; Ahmad, M.U.D.; Chemin, Y. Satellite surveillance of evaporative depletion across the Indus Basin. Water Resour. Res. 2002, 38, 1273.

31. Engman, E.T.; Gurney, R.J. Remote Sensing in Hydrology; Chapman and Hall: London, UK, 1991.

32. Meyer, W.B.; Turner, B.L. Changes in Land Use and Land Cover: A Global Perspective; Cambridge University Press: Cambridge, UK, 1994.

33. Lambin, E.F.; Geist, H.J.; Lepers, E. Dynamics of land use and land cover change in tropical regions. Annu. Rev. Environ. Resour. 2003, 28, 205-241.

34. De Troch, F.P.; Troch, P.A.; Su, Z.; Lin, D.S. Application of remote sensing for hydrological modelling. In Distributed Hydrological Modeling; Abbott, M.B., Refsgaard, J.C., Eds.; Dordrecht: Kluwer, The Netherlands, 1996; pp. 165-191.

35. Engman, E.T.; Schultz, G.A. Future perspectives. In Remote Sensing in Hydrology and Water Management; Schultz, G.A., Engman, E.T., Eds.; Springer: Berlin, Germany, 2000; pp. 445-457.

36. Liou, Y.-A.; England, A.W. Annual temperature and radiobrightness signatures for bare soils. IEEE Trans. Geosci. Remote Sens. 1996, 34, 981-990.

37. Liou, Y.-A.; Tzeng, Y.-C.; Wigneron, J.-P. Probing soil moisture profiles by microwave radiometry over a wheat field. In Remote Sensing and Hydrology; Owe, M., Brubaker, K., Eds.; IAHS Redbook Publications: Wallingford, UK, 2002; Volume 267.

38. Sandholt, I.; Rasmussen, K.; Andersen, J. A simple interpretation of the surface temperature/ vegetation index space for assessment of soil moisture status. Remote Sens. Environ. 2002, 79, 213-224.

39. Stisen, S.; Sandholt, I.; Norgaard, A.; Fensholt, R.; Jensen, K.H. Combining the triangle method with thermal inertia to estimate regional evapotranspiration-Applied to MSG SEVIRI data in the Senegal River basin. Remote Sens. Environ. 2008, 112, 1242-1255. 
40. Quattrochi, D.A.; Luvall, J.C. Thermal infrared remote sensing for analysis of landscape ecological processes: Methods and applications. Landsc. Ecol. 1999, 14, 577-598.

41. Moran, M.S.; Peters-Lidard, C.D.; Watts, J.M.; McElroy, S. Estimating soil moisture at the watershed scale with satellite-based radar and land surface models. Can. J. Remote Sens. 2004, 30, 805-824.

42. Courault, D.; Seguin, B.; Olioso, A. Review on estimation of evapotranspiration from remote sensing data: From empirical to numerical modelling approaches. Irrig. Drain. Syst. 2005, 19, 223-249.

43. Verstraeten, W.W.; Veroustraete, F.; Feyen, J. Assessment of evapotranspiration and soil moisture content across different scales of observation. Sensors 2008, 8, 70-117.

44. Long, D.; Singh, V.P. A Two-source Trapezoid Model for Evapotranspiration (TTME) from satellite imagery. Remote Sens. Environ. 2012, 121, 370-388.

45. Long, D.; Singh, V.P.; Scanlon, B.R. Deriving theoretical boundaries to address scale dependencies of triangle models for evapotranspiration estimation. J. Geophys. Res. Atmos. 2012, 117, D05113.

46. Yang, Y.; Shang, S. A hybrid dual-source scheme and trapezoid framework-based evapotranspiration model (HTEM) using satellite images: Algorithm and model test. J. Geophys. Res. Atmos. 2013, 118, 2284-2300.

47. Moran, M.S.; Jackson, R.D. Assessing the spatial distribution of evapotranspiration using remotely sensed inputs. J. Environ. Qual. 1991, 20, 525-737.

48. Idso, S.B.; Jackson, R.D.; Reginato, R.J. Estimating evaporation: A technique adaptable to remote sensing. Science 1975, 189, 991-992.

49. Weigand, C.L.; Bartholic, J.F. Remote sensing in evapotranspiration research on the Great Plains. In Proceedings of the Great Plains Agricultural Council Evapotranspiration Seminar, Bushland, TX, USA, March 1970; pp. 137-180.

50. Idso, S.B.; Jackson, R.D.; Reginato, R.J. Detection of soil moisture by remote surveillance. Amer. Sci. 1975, 63, 549-557.

51. Idso, S.B.; Schmugge, T.J.; Jackson, R.D.; Reginato, R.J. The utility of surface temperature measurements for the remote sensing of surface soil water status. J. Geophys. Res. 1975, 80, 3044-3049.

52. Jackson, R.D. Evaluating evapotranspiration at local and regional scales. Proc. IEEE 1985, 73, 1086-1096.

53. Moran, M.S.; Jackson, R.D.; Raymond, L.H.; Gay, L.W.; Slater, P.N. Mapping surface energy balance components by combining Landsat Thematic Mapper and ground-based meteorological data. Remote Sens. Environ. 1989, 30, 77-87.

54. Caselles, V.; Sobrino, J.A.; Coll, C. On the use of satellite thermal data for determining evapotranspiration in partially vegetated areas. Int. J. Remote Sens. 1992, 13, 2669-2682.

55. Kustas, W.P.; Norman, J.M. Use of remote sensing for evapotranspiration monitoring over land surfaces. Hydrol. Sci. J. 1996, 41, 495-516.

56. Rango, A. Application of remote sensing methods to hydrology and water resources. Hydrol. Sci. J. 1994, 39, 309-320. 
57. Hatfield, J.L. Evapotranspiration Obtained from Remote Sensing Methods. Adv. Irrig. 1983, 2, $395-416$.

58. Overgaard, J.; Rosbjerg, D.; Butts, M.B. Land-surface modelling in hydrological perspective-A review. Biogeosciences 2006, 3, 229-241.

59. Glenn, E. P.; Huete, A.R.; Nagler, P.L.; Hirschboeck, K.K.; Brown, P. Integrating remote sensing and ground methods to estimate evapotranspiration. Crit. Rev. Plant Sci. 2007, 26, 139-168.

60. Gowda, P.H.; Chavez, J.L.; Colaizzi, P.D.; Evett, S.R.; Howell, T.A.; Tolk, J.A. ET mapping for agricultural water management: Present status and challenges. Irrig. Sci. 2007, 26, 223-237.

61. Farahani, H.J.; Howell, T.A.; Shuttleworth, W.J.; Bausch, W.C. Evapotranspiration: Progress in measurement and modeling in agriculture. Trans. ASABE 2007, 50, 1627-1638.

62. Kalma, J.D.; McVicar, T.R.; McCabe, M.F. Estimating land surface evaporation: A review of methods using remotely sensed surface temperature data. Surv. Geophys. 2008, 29, 421-469.

63. Li, Z.L.; Tang, R.; Wan, Z.; Bi, Y.; Zhou, C.; Tang, B.; Yan, G.; Zhang, X. A review of current methodologies for regional evapotranspiration estimation from remotely sensed data. Sensors 2009, 9, 3801-3853.

64. Mauser, W.; Stephan, S. Modelling the spatial distribution of evapotranspiration on different scales using remote sensing data. J. Hydrol. 1998, 212-213, 250-267.

65. Tang, B.H.; Li, Z.L.; Zhang, R.H. A direct method for estimating net surface shortwave radiation from MODIS data. Remote Sens. Environ. 2006, 103, 115-126.

66. Penman, H.L. Natural evaporation from open water, bare soil and grass. Proc. R. Soc. Lond. A 1948, 194, 120-145.

67. Allen, R.G.; Pereira, L.S.; Raes, D.; Smith, M. Crop Evapotranspiration-Guidelines for Computing Crop Water Requirements; FAO Irrigation and Drainage Paper 56; Food and Agriculture Organization of the United Nations: Rome, Italy, 1998.

68. Zhang, L.; Lemeur, R. Evaluation of daily evapotranspiration estimates from instantaneous measurements. Agric. For. Meteorol. 1995, 74, 139-154.

69. Jiang, L.; Islam, S. An intercomparison of regional latent heat flux estimation using remote sensing data. Int. J. Remote Sens. 2003, 24, 2221-2236.

70. Choudhury, B.J. Estimating evaporation and carbon assimilation using infrared temperature data: vistas in modeling. In Theory and Applications of Optical Remote Sensing; Asrar, G., Ed.; Wiley: New York, NY, USA, 1989; pp. 628-690.

71. Li, F.; Lyons, T.J. Remote estimation of regional evapotranspiration. Environ. Model. Softw. 2002, 17, 61-75.

72. Granger, R.J. Satellite-derived estimates evapotranspiration in the Gediz basin. J. Hydrol. 2000, 229, 70-76.

73. Waters, R.; Allen, R.; Tasumi, M.; Trezza, R.; Bastiaanssen, W. SEBAL. Surface Energy Balance Algorithms for Land, Version 1.0; Idaho Implementation, Advance Training and Users Manual; August 2002.

74. Choudhury, B.J.; Menenti, M. Parameterization of Land Surface Evaporation by means of Location Dependent Potential Evaporation and Surface Temperature Range; Department for Environment, Food and Rural Affairs (Defra): London, UK, 1993; Volume 212, pp. 561-568. 
75. Jackson, R.D.; Idso, S.B.; Reginato, R.J.; Pinter, P.J. Canopy temperature as a crop water stress indicator. Water Resour. Res. 1981, 17, 1133-1138.

76. Van den Hurk, B. Energy balance based surface flux estimation from satellite data, and its application for surface moisture assimilation. Meteorol. Atmos. Phys. 2001, 76, 43-52.

77. $\mathrm{Su}, \mathrm{Z}$. The surface energy balance system (SEBS) for estimation of turbulent heat fluxes. Hydrol. Earth Syst. Sci. 2002, 6, 85-99.

78. Su, Z. A Surface Energy Balance System (SEBS) for estimation of turbulent heat fluxes from point to continental scale. In Advanced Earth Observation-Land Surface Climate; Su, Z., Jacobs, J., Eds.; Publications of the National Remote Sensing Board (BCRS): Delft, The Netherlands, 2001; Volume 01-02, pp. 91-108.

79. Su, Z.; Li, X.; Zhou, Y.; Wan, L.; Wen, J.; Sintonen, K. Estimating areal evaporation from remote sensing. Proc. IEEE Int. 2003, 2, 1166-1168.

80. Su, Z. Hydrological applications of remote sensing. Surface fluxes and other derived variables surface energy balance. In Encyclopedia of Hydrological Sciences; Anderson, M., Ed.; John Wiley and Sons: Hoboken, NJ, USA, 2005.

81. Jia, L.; Su, Z.; van den Hurk, B.; Menenti, M.; Moene, A.; De Bruin, H.A.R.; Yrisarry, J.J.B.; Ibanez, M.; Cuesta, A. Estimation of sensible heat flux using the Surface Energy Balance System (SEBS) and ATSR measurements. Phys. Chem. Earth 2003, 28, 75-88.

82. Wood, E.F.; Su, H.; McCabe, M.; Su, B. Estimating Evaporation from Satellite Remote Sensing. In Proceedings of the 2003 IEEE International Geoscience and Remote Sensing Symposium (IGARSS ’03), Toulouse, France, 21-25 July 2003; Volume 2, 1163-1165.

83. Su, H.; Mccabe, M.F.; Wood, E.F.; Su, Z.; Prueger, J.H. Modeling evapotranspiration during SMACEX: Comparing two approaches for local- and regional-scale prediction. J. Hydrometeorol. 2005, 6, 910-922.

84. Gao, Y.C.; Long, D. Intercomparison of remote sensing-based models for estimation of evapotranspiration and accuracy assessment based on SWAT. Hydrol. Process. 2008, 22, 4850-4869.

85. Roerink, G.J.; Su, Z.; Menenti, M. S-SEBI: A simple remote sensing algorithm to estimate the surface energy balance. Phys. Chem. Earth B 2000, 25, 147-157.

86. Liou, Y.-A.; Chuang, Y.-C.; Lee, T. Estimate of evapotranspiration over rice fields using high resolution DMSV imagery data. In Proceedings of the Cross-Strait Symposium on the Remote Sensing and Agricultural Biotechnology, Chung-li, Taiwan, 2002.

87. Bastiaanssen, W.G.M.; Menenti, M.; Feddes, R.A.; Holtslag, A.A.M. A remote sensing surface energy balance algorithm for land (SEBAL): 1. Formulation. J. Hydrol. 1998, 212-213, 198-212.

88. Bastiaanssen, W.G.M.; Pelgrum, H.; Wang, J.; Ma, Y.; Moreno, J.F.; Roerink, G.J.; van der Wal, T. A remote sensing surface energy balance algorithm for land (SEBAL): 2. Validation. J. Hydrol. 1998, 212-213, 213-229.

89. Bastiaanssen, W.G.M. SEBAL-based sensible and latent heat fluxes in the irrigated Gediz Basin, Turkey. J. Hydrol. 2000, 229, 87-100.

90. Bastiaanssen, W.G.M.; Noordman, E.J.M.; Pelgrum, H.; Davids, G.; Thoreson, B.P.; Allen, R.G. SEBAL model with remotely sensed data to improve water-resources management under actual field conditions. J. Irrig. Drain. E ASCE 2005, 131, 85-93. 
91. Bastiaanssen, W.G.M. Regionalization of surface flux densities and moisture indicators in composite terrain. Ph.D. Thesis, Wageningen Agricultural University, Wageningen, The Netherlands, 1995.

92. Long, D.; Singh, V.P. Assessing the impact of end-member selection on the accuracy of satellite-based spatial variability models for actual evapotranspiration estimation. Water Resour. Res. 2013, 49, 2601-2618.

93. Long, D.; Singh, V.P. A modified surface energy balance algorithm for land (M-SEBAL) based on a trapezoidal framework. Water Resour. Res. 2012, 48, W02528.

94. Long, D.; Singh, V.P.; Li, Z.L. How sensitive is SEBAL to changes in input variables, domain size and satellite sensor? J. Geophys. Res. Atmos. 2011, 116, D21107.

95. Bastiaanssen, W.; Thoreson, B.; Clark, B.; Davids, G. Discussion of "Application of SEBAL Model for Mapping Evapotranspiration and Estimating Surface Energy Fluxes in South-Central Nebraska" by Ramesh K. Singh, Ayse Irmak, Suat Irmak, and Derrel L. Martin. J. Irrig. Drain. E ASCE 2010, 136, 282-283.

96. Gao, Y.C.; Long, D.; Li, Z.L. Estimation of daily actual evapotranspiration from remotely sensed data under complex terrain over the upper Chao river basin in North China. Int. J. Remote Sens. 2008, 29, 3295-3315.

97. Allen, R.G.; Tasumi, M.; Morse, A. Satellite-based evapotranspiration by METRIC and Landsat for western states water management. Presented at the US Bureau of Reclamation Evapotranspiration Workshop, Ft. Collins, CO, USA, 8-10 February 2005.

98. Allen, R.G.; Tasumi, M.; Trezza, R. Satellite-based energy balance for mapping evapotranspiration with internalized calibration (METRIC)-model. J. Irrig. Drain. E ASCE 2007, 133, 380-394.

99. Tasumi, M.; Trezza, R.; Allen, R.G.; Wright, J.L. Operational aspects of satellite-based energy balance models for irrigated crops in the semi-arid U.S. Irrig. Drain. Sys. 2005, 19, 355-376.

100. Long, D.; Singh, V.P. Integration of the GG model with SEBAL to produce time series of evapotranspiration of high spatial resolution at watershed scales. J. Geophys. Res. Atmos. 2010, 115. D21128.

101. Santos, C.; Lorite, I.J.; Tasumi, M.; Allen, R.G.; Fereres, E. Integrating satellite-based evapotranspiration with simulation models for irrigation management at the scheme level. Irrig. Sci. 2008, 26, 277-288.

102. Norman, J.M.; Becker, F. Terminology in thermal infrared remote sensing of natural surfaces. Agric. For. Meteorol. 1995, 77, 153-166.

103. Blyth, E.M.; Harding, R.J. Application of aggregation models to surface heat flux from the Sahelian tiger bush. Agric. For. Meteorol. 1995, 72, 213-235.

104. Huntingford, C.; Allen, S.; Harding, R. An intercomparison of single and dual-source vegetation-atmosphere transfer models applied to transpiration from Sahelian savannah. Bound Lay. Meteorol. 1995, 74, 397-418.

105. Kabat, P.; Dolman, A.J.; Elbers, J.A. Evaporation, sensible heat and canopy conductance of fallow savannah and patterned woodland in the Sahel. J. Hydrol. 1997, 188-189, 494-515.

106. Wallace, J.S. Evaporation and radiation interception by neighbouring plants. Q. J. R. Meteorol. Soc. 1997, 123, 1885-1905.

107. Priestley, C.H.B.; Taylor, R.J. On the assessment of surface heat flux and evaporation using large-scale parameters. Mon. Weather Rev. 1972, 100, 81-92. 
108. Anderson, M.C.; Norman, J.M.; Kustas, W.P.; Houborg, R.; Starks, P.J.; Agam, N. A thermal-based remote sensing technique for routine mapping of land-surface carbon, water and energy fluxes from field to regional scales. Remote Sens. Environ. 2008, 112, 4227-4241.

109. Kustas, W.; Anderson, M. Advances in thermal infrared remote sensing for land surface modeling. Agric. For. Meteorol. 2009, 149, 2071-2081.

110. Anderson, M.C.; Norman, J.M.; Diak, G.R.; Kustas, W.P.; Mecikalski, J.R. A two-source time integrated model for estimating surface fluxes using thermal infrared remote sensing. Remote Sens. Environ. 1997, 60, 195-216.

111. Kustas, W.P.; Norman, J.M. Evaluation of soil and vegetation heat flux predictions using a simple two source model with radiometric temperatures for partial canopy cover. Agric. For. Meteorol. 1999, 94, 13-29.

112. Norman, J.M.; Kustas, W.P.; Prueger, J.H.; Diak, G.R. Surface flux estimation using radiometric temperature: A dual-temperature-difference method to minimize measurement errors. Water Resour. Res. 2000, 36, 2263-2274.

113. Kustas, W.P.; Norman, J.M.; Schmugge, T.J.; Anderson, M.C. Mapping surface energy fluxes with radiometric temperature. In Thermal Remote Sensing in Land Surface Processes; Quattrochi, D.A., Luvall, J.C., Eds.; Taylor and Francis: London, UK, 2003.

114. Li, F.; Kustas, W.P.; Prueger, J.H.; Neale, C.M.U.; Jackson, T.J. Utility of remote sensing based two-source energy balance model under low and high vegetation cover conditions. $J$. Hydrometeorol. 2005, 6, 878-891.

115. Sanchez, J.M.; Kustas, W.P.; Caselles, V.; Anderson, M. Modelling surface energy fluxes over maize using a two-source patch model and radiometric soil and canopy temperature observations. Remote Sens. Environ. 2007, 112, 1130-1143.

116. Sanchez, J.M.; Scavone, G.; Caselles, V.; Valor, E.; Copertino, V.A.; Telesca, V. Monitoring daily evapotranspiration at a regional scale from Landsat-TM and ETM+ data: application to the Basilicata region. J. Hydrol. 2008, 351, 58-70.

117. Wang, K.; Dickinson, R.E. A review of global terrestrial evapotranspiration: Observation, modeling, climatology, and climatic variability. Rev. Geophys. 2012, 50, RG2005.

118. Norman, J.M.; Kustas, W.P.; Humes, K.S. Source approach for estimating soil and vegetation energy fluxes in observations of directional radiometric surface temperature. Agric. For. Meteorol. 1995, 77, 263-293.

119. Anderson, M.C.; Norman, J.M.; Mecikalski, J.R.; Otkin, J.A.; Kustas, W.P. A climatological study of evapotranspiration and moisture stress across the continental United States based on thermal remote sensing: 2. Surface moisture climatology. J. Geophys. Res. 2007, 112, D11112.

120. Renzullo, L.J.; Barrett, D.J.; Marks, A.S.; Hill, M.J.; Guerschman, J.P.; Mu, Q. Multi-sensor model-data fusion for estimation of hydrologic and energy flux parameters. Remote Sens. Environ. 2008, 112, 1306-1319.

121. Roderick, M.L.; Farquhar, G.D.; Berry, S.L.; Noble, I.R. On the direct effect of clouds and atmospheric particles on the productivity and structure of vegetation. Oecologia 2001, 129, 21-30.

122. Carlson, T.N.; Gillies, R.R.; Perry, E.M. A method to make use of thermal infrared temperature and NDVI measurements to infer surface soil water content and fractional vegetation cover. Remote Sens. Rev. 1994, 9, 161-173. 
123. Wang, K.; Wang, P.; Li, Z.; Cribb, M.; Sparrow, M. A simple method to estimate actual evapotranspiration from a combination of net radiation, vegetation index and temperature. J. Geophys. Res. 2007, 112, D15107.

124. Dawson, T.E.; Burgess, S.S.O.; Tu, K.P.; Oliveira, R.S.; Santiago, L.S.; Fisher, J.B. Nighttime transpiration in woody plants from contrasting ecosystems. Tree Physiol. 2007, 27, 561-575.

125. Pinter, P.J., Jr. Effect of dew on canopy reflectance and temperature. Remote Sens. Environ. 1986, 19, 187-205.

126. Wigneron, J.P.; Calvet, J.C.; Kerr, Y. Monitoring water interception by crop fields from passive microwave observations. Agric. For. Meteorol. 1996, 80, 177-194.

127. Heusinkveld, B.G.; Berkowicz, S.M.; Jacobs, A.F.G.; Hillen, W.; Holtslag, A.A.M. A new remote optical wetness sensor and its applications. Agric. For. Meteorol. 2008, 148, 580-591.

128. Sobrino, J.A.; Gómez, M.; Jiménez-Muñoz, J.C.; Oliosob, A.; Chehbouni, G. A simple algorithm to estimate evapotranspiration from DAIS data: Application to the DAISEX campaigns. J. Hydrol. 2005, 315, 117-125.

129. Sobrino, J.A.; Gómez, M.; Jiménez-Muñoz, J.C.; Olioso, A. Application of a simple algorithm to estimate the daily evapotranspiration from NOAA-AVHRR images for the Iberian Peninsula. Remote Sens. Environ. 2007, 110, 139-148.

130. Carlson, T.N.; Capehart, W.J.; Gillies, R.R. A new look at the simplified method for remote sensing of daily evapotranspiration. Remote Sens. Environ. 1995, 54, 161-167.

131. Jiang, L.; Islam, S. Estimation of surface evaporation map over southern Great Plains using remote sensing data. Water Resour. Res. 2001, 37, 329-340.

132. Trezza, R. Evapotranspiration using a satellite-based surface energy balance with standardized ground control. Ph.D. Dissertation, Biological and Irrigation Engineering Department, Utah State University, Logan, UT, USA, 2002.

133. Liu, S.-F.; Liou, Y.-A.; Wang, W.-J.; Wigneron, J.-P.; Lee, J.-B. Retrieval of crop biomass and soil moisture from measured 1.4 and $10.65 \mathrm{GHz}$ brightness temperatures. IEEE Trans. Geosci. Remote Sens. 2002, 40, 1260-1268.

134. Liou, Y.-A.; Liu, S.-F.; Wang, W.-J. Retrieving soil moisture from simulated brightness temperatures by a neural network. IEEE Trans. Geosci. Remote Sens. 2001, 39, 1662-1673.

135. Liou, Y.-A.; Tzeng, Y.C.; Chen, K.S. A neural network approach to radiometric sensing of land surface parameters. IEEE Trans. Geosci. Remote Sens. 1999, 37, 2718-2724.

136. Liou, Y.-A.; Chen, K.-S.; Wu, T.-D. Reanalysis of L-band brightness predicted by the LSP/R model: Incorporation of rough surface scattering. IEEE Trans. Geosci. Remote Sens. 2001, 39, $129-135$.

137. Judge, J.; England, A.W.; Crosson, W.L.; Laymon, C.A.; Hornbuckle, B.K.; Boprie, D.L.; Kim, E.J.; Liou, Y.-A. A growing season Land Surface Process/Radiobrightness model for wheat-stubble in the Southern Great Plains. IEEE Trans. Geosci. Remote Sens. 1999, 37, 152-158.

(C) 2014 by the authors; licensee MDPI, Basel, Switzerland. This article is an open access article distributed under the terms and conditions of the Creative Commons Attribution license (http://creativecommons.org/licenses/by/3.0/). 